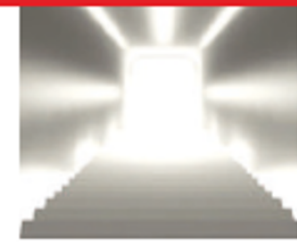

ISIT ADREAM?

Peoplewhohaveneardeath experiences are more

likely to find REM sleep intruding on reality.

uww.nat ure.com/news

\title{
Can super-antibody drugs be tamed?
}

\section{As it becomes clear that the London clinical trial disaster was indeed the fault of the drug itself, Michael Hopkin looks at what went wrong, and whether there is any future for 'superagonist' antibody therapies.}

$T$ here was no warning from animal tests, but last month the experimental antibody drug TGN1412 put six British men in intensive care. The resulting investigation ruled out any failure of experimental and regulatory procedures - a relief for those involved, but a damaging blow for the field. Immunologists are now left asking what went so badly wrong in the trial, and whether the fearsome potency of 'superagonist' antibody therapies will outweigh their promise.

The six volunteers at London's Northwick Park Hospital were probably struck by a huge immune reaction called a cytokine storm - a flood of inflammatory molecules released by cells called helper $\mathrm{T}$ cells, which shut down their organs in hours (see Nature 440, 338-339; 2006). The UK Medical and Healthcare products Regulatory Agency, which approved the trial, announced last week that it has found no evidence of contamination in the treatments, which means the devastating effects were almost certainly caused by TGN1412 itself.

With hindsight, it might be no surprise that the compound, dubbed a 'superagonist' antibody

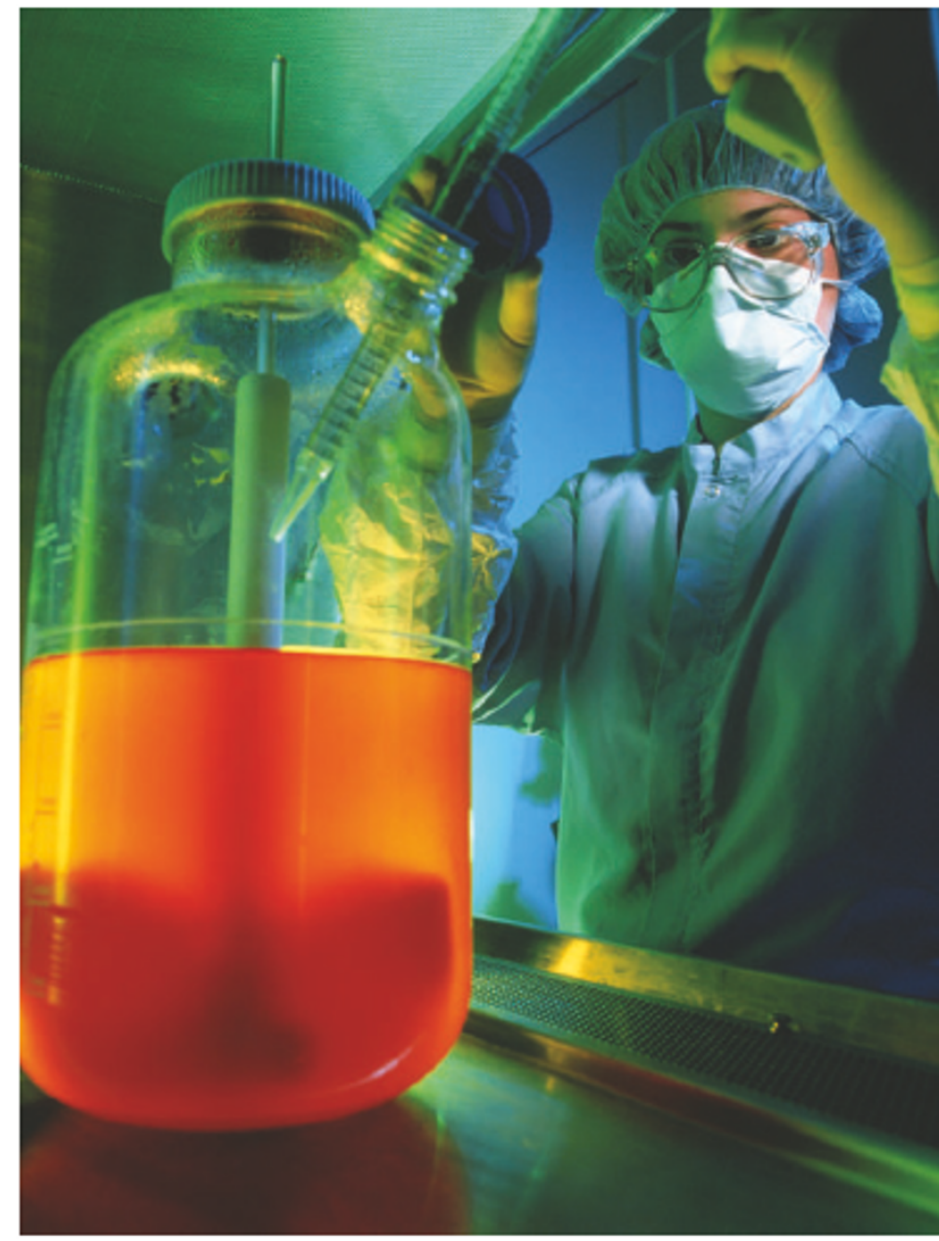

Gathering stor m? Antibody therapies aimed at large swathes of the immune system might be too hot to handle.

elements of the immune system. Roughlyhalf of killer T cells, and virtually all helper and regulatory $\mathrm{T}$ cells, express the CD28 receptor.

When Thomas Hünig, an immunologist at the University of Würzburg and researchers at TeGenero, the spin-off company he co-founded to develop TGN1412, began testing the antibody on animals, they found that the drug seemed only to activate regulatory $\mathrm{T}$ cells (Beyersdorf, N. et al. J. Exp. Med. 202, $445-455 ; 2005)$. This made it an enticing candidate for treating autoimmune diseases such as rheumatoid arthritis and type-1 diabetes. The researchers hoped that TGN1412 could make immunosuppressive cells soothe sites of overinflammation, while the rest of the immune system carried on as usual.

It is still not clear why, when TGN1412 affected only regulatory $\mathrm{T}$ cells in animals, the same almost certainly did not occur in the human trial. It is likely that in humans the super-antibody activated helper $\mathrm{T}$ cells en masse, triggering a cytokine storm.

${ }^{\circ}$ We were shocked and surprised to see what happened in humans, Hünig told Nature. In preclinical trials, monkeys got a by its creators, could run amok in the immune system. Around 20 antibody therapies are currently approved or nearing approval, most of which mimic natural human antibodies against specific viruses or cancer-cell types. But TGN1412 is different. It was designed to circumvent the usual checks and balances that prevent $\mathrm{T}$ cells from overreacting in the course of their normal duties.

Usually, $\mathrm{T}$ cells respond to

receptor (TCR) and the CD28 receptor. TCR binding is specific to the antigen in question, whereas CD28 binding acts more like a 'go' switch for the $\mathrm{T}$ cell; both are normally required (see graphic, over-
"With hindsight, it might be no surprise that the compound could run amok in the immune system" leaf). But the makers of TGN1412 found a way to switch on the CD28 green light without TCR binding, activating $\mathrm{T}$ cells across the board.

$\mathrm{T}$ cells fall into three broad categories: killers, which desspecific enemies, or antigens, recognized by the immune system. After the antigen is first encountered, an 'antigen-presenting cell' binds to a $T$ cell at two sites on its surface: the T-cell troy specific target cells; helpers, which boost other parts of the immune system and are the most likely source of a cytokine storm; and regulatory $\mathrm{T}$ cells, which suppress other dose 500 times that given to the human volunteers, and the monkey $\mathrm{CD} 28$ receptor is identical to the human one, says Hünig. This means that the effects in the monkey trial should have been comparable.

One possible source of the difference between the animal and human trials is that the 'tail' of the antibody molecule at the opposite end from the CD28-binding site may not be the same in humans and monkeys. Antibody tails can undergo a process called crosslinking, which amplifies an immune response by recruiting more immune cells or antibodies. Therapeutic antibodies are modified so that they have the same overall structure as a generic human antibody, but doing 
this may also have prevented the full extent of TGN1412's activity from showing up in animal tests. Hünig admits that this could have happened.

Hünig's team should have known of previous research on this region, says Camilo Colaco of ImmunoBiology, an immunological research company in Cambridge, UK. Similar work has been done on $\mathrm{CD} 3$ receptors, which are crucial for the TCR component of T-cell activation, he says. Researchers were hoping that a superagonist antibody directed at this receptor could boost general T-cell activity, helping transplant patients restore their immune systems after taking immunosuppressive drugs.

\section{Indiscriminate killers}

But in tests of the antibody in mice, researchers found that uncontrolled cytokine release was a problem - albeit not a large one because the mice were already immunodepleted (L. Chatenoud et al. Transplantation 49, 697-702; 1990). Tweaks to the antibody's tail to prevent crosslinking resulted in an antibody that did not have the same problem and could enter clinical trials (P. A. Carpenter et al. Biol. Blood Marrow Transplant. 11, 465-471; 2005); the drug has now been approved under the name visilizumab. But using unmodified superagonists in a healthy volunteer with an intact immune system is playing with fire, says Colaco: "It would go bananas."

Another, more controversial, theory is that, in humans, CD28 receptors are found in the immune system beyond just $T$ cells. Dorothy Lewis, an immunologist at Baylor College of Medicine in Houston, Texas, says that the receptor may be present on granulocytes, the most numerous white blood cells in the body, which have a range of cell-killing tricks. Alternatively, killer $\mathrm{T}$ cells might have been triggered to release a cell-destroying molecule called granzyme B. These processes could theoretically produce the effect seen in the TGN1412 trial, says Lewis. She also suggests that a cytokine storm might come on too slowly to account for the reaction seen in the trial volunteers, all of whom suffered severe effects within minutes and collapsed within 12 hours of being injected with TGN1412. "When you trigger T cells it takes a while to get up to speed," she says. "But granulocytes are good to go."

Hünig doesn't buy her theory, however. After the trial went

\section{"My first reaction} was 'how did they get that through the regulatory body?"'
Normal T-cell activation

To switch on a T cell, two signals are required: a general activation trigger and a specific 'antigen' from a molecule recognized as being foreign.

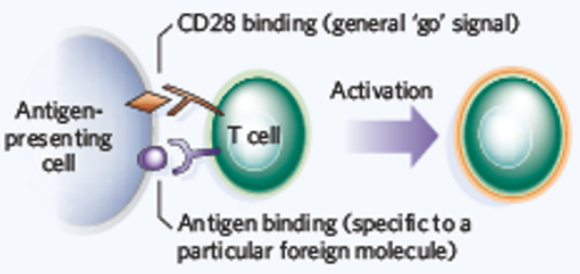

What happened in animal trials In monkeys, TGN1412 activated only regulatory $T$ cells, which damp other elements of the immune response. So the researchers hoped the drug would help treat autoimmunediseases by suppressing the inflammatory immune cells (red) that attack the patient's own tissue.

What probably happened in the London trial As well as activating regulatory $T$ cells. TGN1412 switched on helper T cells (blue) which produce chemical messengers called cytokines that boost other elements of the immune response. This mass activation T cells caused a devastating 'cytokine storm' - a flood of inflammatory molecules that swept through the patients' bodies.

on granulocytes (K. Venuprasad et al. Eur. J. Immunol. 31, 1536-1543; 2001), and he is confident that the idea can be ruled out. Hünig remains convinced that overactivation of helper T cells was to blame: "It was not too fast to be cytokines."

\section{Proceed with caution}

Some, such as Steve Anderton, an immunologist at the University of Edinburgh, UK, who is studying the use of antibodies to overcome cancers that evade the immune system, are concerned at the haste with which TGN1412 was tried out in humans - barely a year after the structure of the CD28 receptor was deduced (E. J. Evans et al. Nature Immunol. 6, 271-279; 2005). "It is flabbergasting that this approach was tried, he says. "It takes away all the rules of the immune response." Jim Riley of the University of Pennsylvania in Philadelphia, who works on the CD28 pathway, feels similarly. ${ }^{\alpha} \mathrm{My}$ first reaction was 'how did they get that through the regulatory body? ${ }^{\text {mo }}$ he says.

A major question now is wrong, he says he went over the literature to see if $\mathrm{CD} 28$ receptors might be more common than he had imagined. He says that only one group has ever claimed to have spotted them how the field can move forward. Instead of risking further work with superantibodies, some favour turning to other approaches. One option is to culture a patient's regulatory
Super-antibody $\mathrm{T}$-cell activation

This overrides both signals and poten tially activates all T cells with a CD28 receptor, not just those specific for a particular antigen.
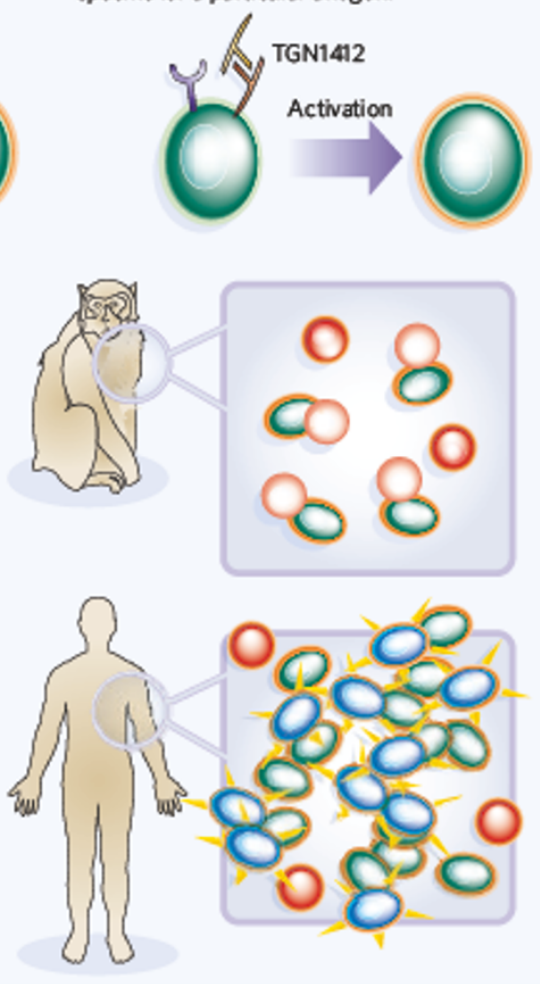

$\mathrm{T}$ cells in the lab, then inject them into the bloodstream. Another is to target processes such as the binding of antigen-presenting cells to $\mathrm{T}$ cells using blocking antibodies. This method allows autoimmune disease to be treated without activating regulatory $\mathrm{T}$ cells, and has alreadybeen tested on a mouse model of multiple sclerosis (H. D. Lum et al. Leukocyte Biol; in the press).

But others feel that superantibody therapy does have a future. The CD3 superantibody visilizumab suggests that such drugs can be safe. And Anderton says that the $\mathrm{CD} 25$ receptor, which is expressed mainly by regulatory $\mathrm{T}$ cells, and by other $\mathrm{T}$ cells only once they are activated, may be a safer target than CD28.

TeGenero's future is unclear - it has a staff of just 15 people, and TGN1412 was its only product. The company seems hopeful that the technology can be tamed: ${ }^{\alpha}$ It is too early to give definitive answers on how superagonistic antibodies must be developed in the future," TeGenero said in a statement to Nature. "Dangers can possibly be reduced by very careful assessment of pharmacological as well as safety characteristics."

But the idea of using superantibodies to activate the $\mathrm{CD} 28$ receptor is almost certainly dead. "In its current form I wouldn't want to have anything to do with it," says Riley. 